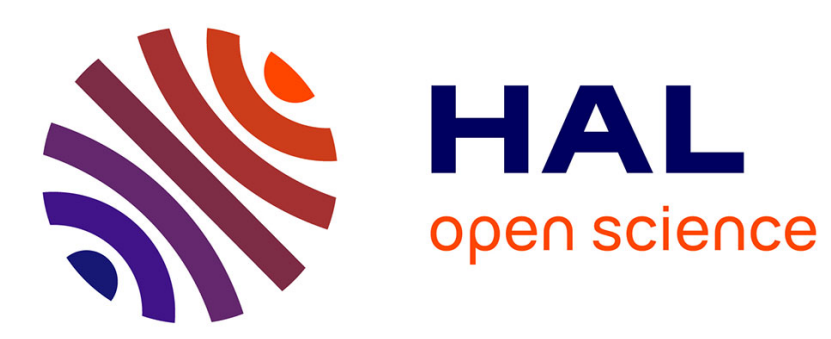

\title{
To what extent are African education policies pro-poor? Jean-Claude Berthélemy
}

\section{To cite this version:}

Jean-Claude Berthélemy. To what extent are African education policies pro-poor?. 2004. halshs03322220

\section{HAL Id: halshs-03322220 \\ https://shs.hal.science/halshs-03322220}

Submitted on 18 Aug 2021

HAL is a multi-disciplinary open access archive for the deposit and dissemination of scientific research documents, whether they are published or not. The documents may come from teaching and research institutions in France or abroad, or from public or private research centers.
L'archive ouverte pluridisciplinaire HAL, est destinée au dépôt et à la diffusion de documents scientifiques de niveau recherche, publiés ou non, émanant des établissements d'enseignement et de recherche français ou étrangers, des laboratoires publics ou privés. 

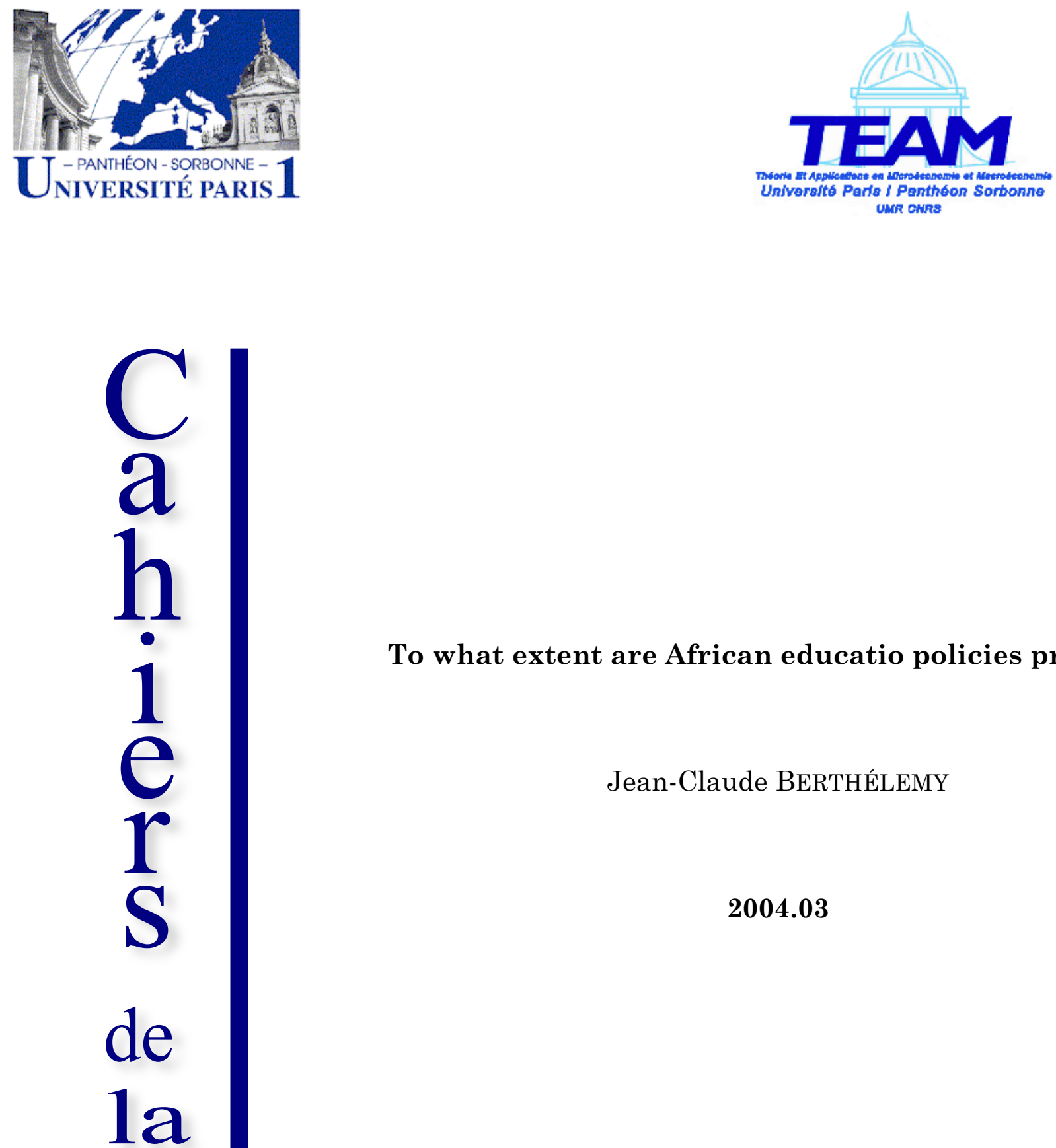

To what extent are African educatio policies pro-poor?

Jean-Claude BERTHÉLEMY

2004.03
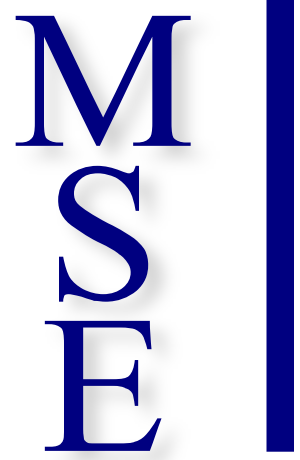

CENTRE NATIONAL

DE LARECHERCHE

SCIENTFIQUE

Maison des Sciences Économiques, 106-112 boulevard de L'Hôpital, 75647 Paris Cedex 13 


\title{
To what extent are African education policies pro-poor?
}

\author{
Jean-Claude Berthélemy* \\ University Paris 1 Panthéon Sorbonne, TEAM - CNRS, Maison des Sciences Economiques, 106-112 Bd de \\ l’Hopital, 75647 Paris Cedex 13, France, email address: berthele@univ-paris1.fr.
}

January 2004

* This paper has greatly benefited from discussions at the conference "L'éducation, fondement du développement durable en Afrique" organised by the Institut de France (Paris, November, 2002), as well as in seminars given in Bamako (Institut des Hautes Etudes de Management, February 2003), Ouagadougou (Centre d'Analyse des Politiques Economiques et Sociales, April 2003), Addis Ababa (Symposium of the African Development Bank Group meetings, June 2003) and Paris (first academic workshop of the European Development Research Network, November 2003). All errors and shortcomings are mine. 
Résumé

Ce papier discute la nature distributive des politiques éducatives dans les pays en développement, avec un accent particulier mis sur le cas de l'Afrique sub-saharienne. Nous montrons que la distribution du capital humain est particulièrement inégalitaire en Afrique sub-saharienne, de même que dans la région Afrique du Nord - Moyen Orient et en Asie du Sud. Ceci est montré après avoir corrigé les données pour la corrélation inévitable qui existe entre le niveau moyen du capital humain et sa concentration. Nous montrons en complément, à partir de données de structure de la scolarisation en Afrique sub-saharienne, des éléments montrant que ces pays accordent relativement peu d'attention à l'éducation primaire par comparaison à l'éducation secondaire. Nous interprétons ce biais comme le résultat de caractéristiques institutionnelles spécifiques à l'Afrique sub-saharienne, liées à son histoire (notamment son héritage post-colonial), sa démographie et sa géographie.

Mots-clés: éducation, politique distributive, institutions, Afrique

\section{Abstract}

This paper discusses the distributive nature of education policies in developing countries, with a specific emphasis on sub-Saharan Africa. We show that human capital is particularly unequally distributed in sub-Saharan African countries and in Middle-East and North Africa and South Asian regions as well, after taking into account the inevitable (arithmetical) correlation which exists between the aggregate level of human capital and its concentration. We provide further evidence, based on sub-Saharan African schooling structure data, that these countries pay, relatively speaking, little attention to primary education, to the benefit of secondary education. We interpret this bias as the result of specific institutional characteristics of sub-Saharan Africa, which are deeply-rooted in its history (in particular its post-colonial legacy), its demography and its geography.

Keywords: Education, distributive policy, institutions, Africa

JEL classification: D31, I28, O15 


\section{Introduction}

Under donors' guidance, poor countries, in particular in sub-Saharan Africa, have started developing new strategies to fight poverty, in the framework of the preparation of Poverty Reduction Strategy Papers. One of the main pillars of such strategies is the investment in education, which represents on average 40 percent of PRSP-related public expenditure.

This strategy relies on two assumptions: education is good for growth, which is a necessary ingredient of poverty alleviation strategies, and public education may help reducing inequality through distributing assets, in the form of human capital, to large segments of the population.

The first assumption has been frequently questioned in the recent literature (Pritchett, 2001), although at the micro-economic level there is little doubt that education has a high pay-off (Psacharopoulos, 1994). One main reason why the macro-economic impact of education policies on growth is sometimes insignificant is related to the existence of rent-seeking behaviours: if people who are educated use their talents in rent-seeking activities instead of in production of goods and services, their human capital will have, at the micro-economic level, a very high private return, but will have not any positive impact on aggregate income and economic growth (Berthélemy, Pissarides and Varoudakis, 1998).

It is also possible that the distribution of education affects its growth impact, as suggested by econometric estimations produced by Castello and Domenech (2002). In theory, there is an optimal degree of concentration of human capital if the micro-economic relation between education and income is concave, which would imply that the relation between aggregate income and human capital concentration has an inverted U-shape (Lopez, Thomas and Wang, 1998). However, assuming that the Mincer theory of earnings is valid, this relation is convex instead of concave, which invalidates the previous argument.

Whatever its impact on growth, an unequal education policy will presumably increase, rather than decrease income inequality among the population, which would lead to question the second assumption underlying the emphasis given to education in PRSPs. Recent calculations of the Gini coefficient of the distribution of human capital suggest that its concentration in 
sub-Saharan Africa is among the highest in the world (Thomas, Wang and Fan, 2000), as reported in section 2. It may be however contended that such data are misleading, because there is a negative correlation between the level of human capital and its concentration, as empirically shown by Thomas, Wang and Fan (2000), which means that countries with low educational level will have high education inequality. In section 3, we examine this relation between the aggregate level of human capital and its concentration on theoretical grounds. This exercise suggests a functional relation between the two, and leads to distinguish the effects of the level and of the structure of human capital on its concentration. In section 4, we show the analytical implications of such a distinction, both for the study of the impact of education policy on income levels, and for the analysis of its impact on income distribution. In section 5, we provide an empirical test of the previously established relation between the level and the concentration of education. This test is consistent with the analytical findings of section 3; moreover, it suggests also that, notwithstanding their lower level of human capital, sub-Saharan African countries, but also countries in the Middle-East and North Africa (MENA) and South-Asian regions, implement on average significantly more inequitable education policies than other countries. In section 6 , we have a further look at sub-Saharan education data, using school enrolment ratios, and we show that these countries pay on average, relatively speaking, much more attention to secondary education than to primary education, which confirms the previous assessment. In section 7, we suggest that this behaviour is the result of an institutional bias, deeply rooted in historical and political economy characteristics of sub-Saharan African countries. Section 8 concludes.

\section{Preliminary discussion of data}

We use here a standard definition of human capital, i.e. the number of years of schooling of working-age individuals. This asset is unequally distributed among the population, and to measure this inequality we use the Gini concentration index, calculated on the distribution of human capital instead of on the distribution of income. Such Gini indexes of concentration of human capital, calculated by Thomas, Wang and Fan (2000), tell us that on average human capital is highly concentrated in sub-Saharan Africa: it was on average equal to 0.61 in subAfrican Africa in 1990, and varied within the region from 0.44 (Mauritius) to 0.91 (Mali). As shown in Figure 1, the degree of concentration of human capital in sub-Saharan Africa is only slightly overtaken by that observed in South Asia, and is much higher than in other regions. 
Figure 1 Evolution of average Gini indexes of human capital by region

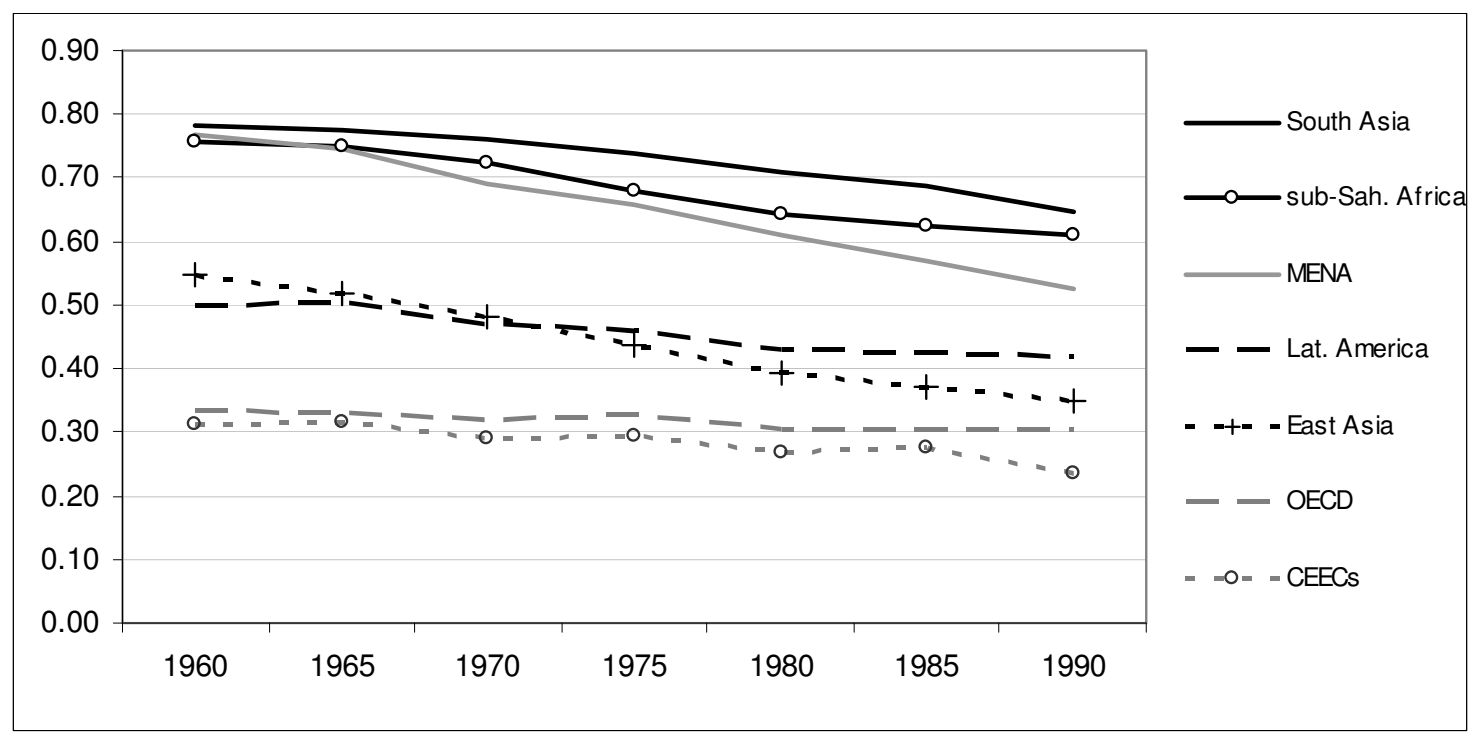

For some part, this observation results from the fact that the level of educational development of sub-Saharan Africa is extremely weak. Indeed, there is a very significant negative correlation, in the data produced by Thomas, Wang and Fan (2000), between the aggregate human capital of a country, and its human capital Gini index.

This correlation can be intuitively explained as follows: when the educational average level is weak, there are numerous individuals who do not have any education, so that the mode of the distribution of human capital is close to zero, leading to a high value of the Gini index. On the contrary, when education is high, it is also generalized in the whole population, so that practically all the individuals, even the most deprived, have a non-negligible human capital. At the upper end of the distribution, the number of year of studies of the individuals the best endowed in human capital has an upper limit, defined by the usual length of the university curriculums, which implies that, from a certain point, an increase of the aggregate human capital benefits inevitably to larger segments of the population.

One may have the intuition that, since sub-Saharan Africa (as well as South Asia and MENA) is today at a level development comparable to that of East Asia in 1960, it has presumably a more regressive policy: its Gini index for 1990 is much higher than that of East Asia and Latin America for 1960. But we need to properly tests and quantify these differences. For that 
matter, we develop in the following section a simplified analytical framework, which is useful to provide a more precise interpretation of the observed between the aggregate level and the concentration of human capital and disentangle, in data reported in Figure 1, what is due to the diversity of levels of educational development and what is due to differences in the implicit distributive policies implemented by governments through their education policies.

\section{Analytical framework}

We consider that there are 4 classes of individuals: those who have no education, those who have attended primary school, those who have attended secondary school, and finally those who have followed a university program. We neglect in this example the distribution of the population by level of schooling attained within each of the four classes. This amounts to suppose that the essential disparity which exists in the distribution of education is associated with the access to the successive cycles, rather than with drop-outs and repetition in the course of each cycle. This hypothesis is besides used also by the authors who have calculated indicators of concentration of human capital (Thomas, Wang and Fan,2000, and Castello and Domenech, 2002), for lack of data on intra-class distribution of human capital.

A second simplifying hypothesis - which role is still only to simplify calculations - consists in assuming that the duration of the curriculum of the individuals who have pursued a secondary cycle is the double of that of the individuals who have got only primary education. Considering the fact that the duration of these cycles is relatively comparable - if one takes into account the fact that few pupils continue until the end of the secondary cycle in developing countries - this hypothesis will have a limited influence on our results. Also we suppose that the tertiary cycle represents the triple of the primary cycle.

Finally, we develop here only a static framework, assuming that the education system is at a steady state.

We define $s_{1}$ as the probability that an individual reaches primary education, $s_{2}$ the probability that he reaches secondary education and $s_{3}$ the one that he reaches higher education. The distribution of human capital in the population will be then the following: 
- $\quad$ A proportion $1-s_{1}$ has a human capital $=0$

- $\quad$ A proportion $s_{1}-s_{2}$ has a human capital $=1$

- A proportion $s_{2}-s_{3}$ has a human capital $=2$

- $\quad$ A proportion $\mathrm{s}_{3}$ has a human capital $=3$

In this example the aggregated human capital $H$ is simply:

$H=s_{1}-s_{2}+2\left(s_{2}-s_{3}\right)+3 s_{3}=s_{1}+s_{2}+s_{3}$

and the Lorenz curve of human capital can be drawn as in Figure 2:

Figure 2: Lorenz curve of human capital

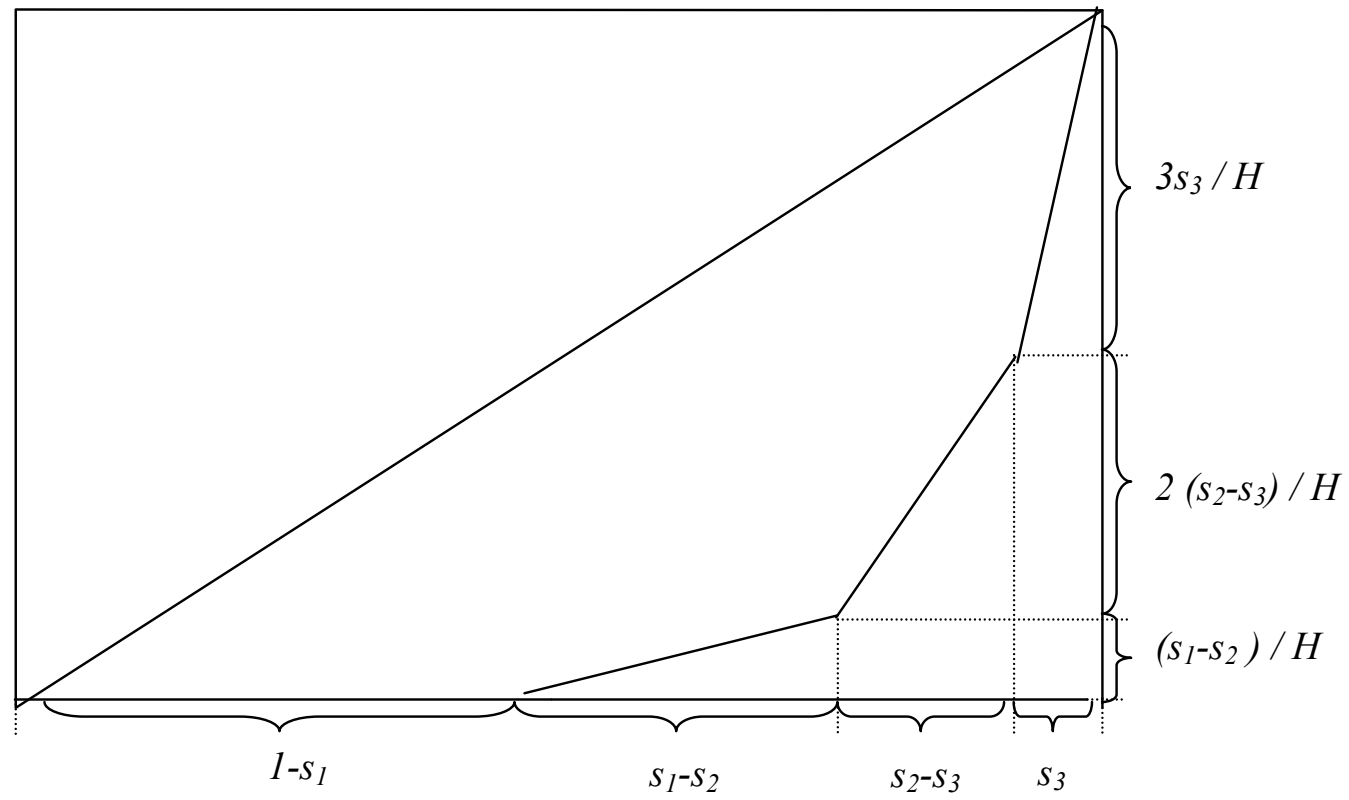

Under these assumptions the Gini concentration index, which is defined as the double of the surface included between the diagonal and the Lorenz curve, is equal to:

$G=1-\frac{2}{H}\left[0+\frac{1}{2}\left(s_{1}-s_{2}\right)^{2}+\frac{2}{2}\left(s_{2}-s_{3}\right)^{2}+\frac{3}{2}\left(s_{3}\right)^{2}+s_{2}\left(s_{1}-s_{2}\right)+2 s_{3}\left(s_{2}-s_{3}\right)\right]$ 
which, after grouping of terms, can be written as:

$G_{H}=1-\frac{1}{H}\left[\left(s_{1}\right)^{2}+\left(s_{2}\right)^{2}+\left(s_{3}\right)^{2}\right]$

This expression can be also re-written as follows:

$G_{H}=1-H\left[1-2 \frac{s_{1} s_{2}+s_{2} s_{3}+s_{1} s_{3}}{H^{2}}\right]$

If one calls $\sigma$ the ratio between the rates of secondary and primary schooling $\left(\sigma=s_{2} / s_{1}\right)$ and $\tau$ the ratio between the rates of higher and primary schooling $\left(\tau=s_{3} / s_{1}\right)$, one obtains then :

$G_{H}=1-H\left(1-2 \frac{\sigma+\tau+\sigma \tau}{(1+\sigma+\tau)^{2}}\right)$

This expression shows that, for a given structure of the schooling ratios $(\sigma, \tau), 1-G_{H}$ is proportional to human capital $H$. The expression between brackets is not a monotonous function of $\sigma$ and of $\tau$, it is then difficult to predict how it will evolve with education policies. However, if we consider a model with only primary and secondary education, it appears clearly that $G_{H}$ increases with $\sigma$. Also, for relatively small value of $\tau$ (which corresponds to stylized facts in developing countries), $G_{H}$ is clearly increasing with $\sigma$ and $\tau$.

\section{Disentangling level and distribution effects of human capital accumulation}

Our previous result clarifies the negative effect of human capital level on its dispersion. Before providing an empirical test of this formula, we show in this section that this result can contribute to the analysis on the impact of education policies on both agregate income and income distribution, because it helps to disentangle the level and distribution effects of human capital accumulation. We consider first briefly the question of the impact of education on aggregate income, and then we focus our discussion on distributional issues. 
As mentioned in introduction, although there is little doubt at the micro-economic level that higher human capital increases income, the corresponding aggregate relation is difficult to establish empirically, in particular in comparative growth analysis. One reason for that may be due to changes in the characteristics of the distribution of human capital when its level increases. If the micro-economic relation between human capital and income is convex, as in the Mincer theory, the concentration of human capital has a positive effect on aggregate income. As a consequence, human capital accumulation has two contradicting effects: it increases aggregate income through an increase of its level, for a given concentration, and it decreases income through a reduced concentration. Separating these two effects would be necessary to avoid the usual muddled results in growth equations. However, when both human capital level and human capital concentration are introduced simultaneously in growth equations, parameter estimates cannot be robust, due to the very high correlation between these two variables, illustrated in section $2 .{ }^{1}$ For that matter, being able to separate the impact of the aggregate education level on its concentration from other factors influencing this concentration is useful.

Similarly, our result may contribute to the analysis of the impact of human capital accumulation on income distribution. In the previous literature on human capital and income distribution, it has been generally accepted that the relation between human capital and the concentration of income distribution has an inverted U-shape. This relation may lead to a Kuznets curve (see in particular Knight and Sabot, 1983). However, as we show below, this relation mixes-up two effects: an effect of the level of human capital, and an effect of its concentration.

More precisely, in the previous literature, theoretical models used to study the relation between education and income distribution relied on one single parameter to characterise educational achievement. For instance, in Knight and Sabot, the discussion is focused on the proportion of individuals who have been educated. In our setting, this amounts to neglect parameters $s_{2}$ and $s_{3}$, and to focus the discussion on $s_{1}$. In this context the specific impact of the concentration of human capital on income concentration is overlooked. A higher human capital means a higher $s_{1}$, which in turns means a lower $G_{H}$ (which is in this case equal to 1 $\left.s_{1}\right)$.

\footnotetext{
${ }^{1}$ See Castello and Domenech (2001) for such an exercise.
} 
In a more general framework, human capital accumulation will have two separate effects on income distribution. First, when more education means more equally distributed education, a higher $H$ may reduce $G_{H}$, which will intuitively reduce $G_{Y}$. We call this the concentration effect. Second, for a given structure of distribution of education (i.e. for a given $G_{H}$ ), a higher $H$ increases all incomes, but will have a higher positive impact on the income of well educated individuals than on the income of uneducated individuals, assuming a Mincer income function; this in turn should increase income concentration. We call this latter effect the level effect. In the simple case corresponding to the previous literature, these two effects are mixed up, which leads to the usual Kuznets curve results because the level effect initially dominates, while the concentration effect dominates for higher levels of schooling.

To discuss this further in our framework, we need first to compute the Gini index of concentration of incomes. In order to keep our theoretical model as simple as possible, we assume that all incomes are labour incomes, and that the income of an individual is related to its human capital, through a Mincer function. We have therefore four categories of income, which we name $y_{0}, y_{1}, y_{2}$, and $y_{3}$, for individuals who have respectively no education, primary education, secondary education and higher education, and where the $y_{i}$ will be exponentially growing with $i$. With these assumptions, computing the Gini index of income concentration (which we name $G_{Y}$ ) is similar to computing the Gini index of human capital concentration provided in the previous section.

$G_{Y}=1-\frac{1}{Y}\left[\begin{array}{l}y_{0}\left(1-s_{1}\right)^{2}+y_{1}\left(s_{1}-s_{2}\right)^{2}+y_{2}\left(s_{2}-s_{3}\right)^{2}+y_{3}\left(s_{3}\right)^{2}+2 y_{2} s_{3}\left(s_{2}-s_{3}\right)+2 y_{1} s_{3}\left(s_{1}-s_{2}\right) \\ +2 y_{0} s_{3}\left(1-s_{1}\right)+2 y_{1}\left(s_{2}-s_{3}\right)\left(s_{1}-s_{2}\right)+2 y_{0}\left(s_{2}-s_{3}\right)\left(1-s_{1}\right)+2 y_{0}\left(s_{1}-s_{2}\right)\left(1-s_{1}\right)\end{array}\right]$

where $\mathrm{Y}$ is the average income, defined as :

$Y=y_{0}+\left(y_{1}-y_{0}\right) s_{1}+\left(y_{2}-y_{1}\right) s_{2}+\left(y_{3}-y_{2}\right) s_{3}$

After grouping of terms, $G_{Y}$ can be written as:

$G_{Y}=1-\frac{1}{Y}\left[y_{0}+\left(y_{1}-y_{0}\right)\left(s_{1}\right)^{2}+\left(y_{2}-y_{1}\right)\left(s_{2}\right)^{2}+\left(y_{3}-y_{2}\right)\left(s_{3}\right)^{2}\right]$ 
In the case where only one category of education is considered, $G_{Y}$ becomes equal to

$G_{Y}=1-\frac{y_{0}+\left(y_{1}-y_{0}\right)\left(s_{1}\right)^{2}}{y_{0}+\left(y_{1}-y_{0}\right) s_{1}}$

which has the usual inverted U-shape form, with a maximum for

$s_{1}^{*}=\frac{\sqrt{1+\rho}-1}{\rho}$

where $\rho$ is the rate of return of education, i.e.:

$\rho=\frac{y_{1}-y_{0}}{y_{0}}$

In a more general framework, we need to study the impact of education policies separately through its level effect and its concentration effect; For that matter, we need at least two parameters to characterise such policies. We propose here a simple exercise, where we assume that there is only primary and secondary education, which means that we neglect changes in the higher education enrolment rates. In this framework, we can easily define the marginal impact of the education level $G_{H}$ on $G_{Y}$ for a given level $H$, and conversely the marginal impact of $H$ on $G_{Y}$ for a given concentration $G_{H}$. To do so, we first compute the partial derivatives of $G_{Y}$ with respect to $s_{1}$ and $s_{2}$, and then we combine them to compute the total derivative of $G_{Y}$ with respect to $H$ (along a $G_{H}=$ constant curve) and the total derivative of $G_{Y}$ with respect to $G_{H}$ (along a $H=$ constant curve).

$$
\begin{aligned}
& \frac{\partial G_{Y}}{\partial s_{1}}=\frac{y_{1}-y_{0}}{Y}\left[1-G_{Y}-2 s_{1}\right] \\
& \frac{\partial G_{Y}}{\partial s_{2}}=\frac{y_{2}-y_{1}}{Y}\left[1-G_{Y}-2 s_{2}\right]
\end{aligned}
$$


In what follows, in order to concentrate the analysis to the most relevant cases, we shall assume that the partial derivative of $G_{Y}$ with respect to $s_{1}$ is negative (i.e. more primary education reduces income concentration, when other education enrolment rates are kept constant), which needs only that $s_{1}$ be higher that $\left(1-G_{Y}\right) / 2$. This assumptions usually corresponds to stylised facts, even for countries where education is poorly developed (assuming an income concentration index equal to 0.4 , this implies a primary enrolment rates above $30 \%$ ). We shall also assume that the partial derivative of $G_{Y}$ with respect to $s_{2}$ is negative (i.e. more secondary education increases income concentration, when other education enrolment rates are kept constant); this assumption is also consistent with stylised facts of developing countries, where secondary enrolment rates are typically low.

On a curve $H=$ constant, the following relation applies:

$d s_{1}+d s_{2}=0$

Along this curve, variations of $s_{1}$ are linked to variations of $G_{H}$ through the following equation:

$-d G_{H}=\frac{2}{H}\left(s_{1}-s_{2}\right) d s_{1}$

Therefore:

$\left.\frac{d G_{Y}}{d G_{H}}\right|_{H=c o n s \tan t}=\frac{-H}{2\left(s_{1}-s_{2}\right) Y}\left[\left(y_{1}-y_{0}\right)\left(1-G_{Y}-2 s_{1}\right)-\left(y_{2}-y_{1}\right)\left(1-G_{Y}-2 s_{2}\right)\right]$

Assuming a Mincerian income equation leads to:

$\frac{y_{1}-y_{0}}{y_{0}}=\frac{y_{2}-y_{1}}{y_{1}}=\rho$

Therefore, after some simplifications: 
$\left.\frac{d G_{Y}}{d G_{H}}\right|_{H=c o n s \tan t}=\frac{H\left(y_{1}-y_{0}\right)}{Y}\left[1+\rho \frac{1-G_{Y}-2 s_{2}}{2\left(s_{1}-s_{2}\right)}\right]$

For a rate of return education not higher than $100 \%$, this expression is positive.

Consider now the impact of $\mathrm{H}$ along a $G_{H}=$ constant curve. Along this curve the following relation applies:

$2 s_{1} d s_{1}+2 s_{2} d s_{2}=\left(1-G_{H}\right) d H=\left(1-G_{H}\right)\left(d s_{1}+d s_{2}\right)$

Therefore:

$d s_{1}=\left[\frac{1-G_{H}-2 s_{2}}{2\left(s_{1}-s_{2}\right)}\right] d H$

and

$d s_{2}=\left[\frac{1-G_{H}-2 s_{1}}{2\left(s_{2}-s_{1}\right)}\right] d H$

Consequently:

$\left.\frac{d G_{Y}}{d H}\right|_{G_{H}=c o n s \tan t}=\frac{y_{1}-y_{0}}{2\left(s_{1}-s_{2}\right) Y}\left[\left(1-G_{H}-2 s_{2}\right)\left(1-G_{Y}-2 s_{1}\right)-(1+\rho)\left(1-G_{H}-2 s_{1}\right)\left(1-G_{Y}-2 s_{2}\right)\right]$

which leads to:

$\left.\frac{d G_{Y}}{d H}\right|_{G_{H}=\text { cons tan } t}=\frac{y_{1}-y_{0}}{Y}\left[G_{H}-G_{Y}-\rho \frac{\left(1-G_{H}-2 s_{1}\right)\left(1-G_{Y}-2 s_{2}\right)}{2\left(s_{1}-s_{2}\right)}\right]$

Under previously mentioned conditions, this expression is positive, given that, by construction $G_{H}$ is higher than $G_{Y}$. 
We can conclude from these results that, for a wide variety of situations of developing countries, the Gini coefficient for incomes is increasing with human capital accumulation, when one controls for the concentration of this human capital.

Our results suggest that, instead of testing an inverted U-shape between human capital and income concentration, it would be preferable to separate the impact of the human capital level, for a given concentration of human capital, on one hand, and the impact of human capital concentration, for a given level of human capital, on the other hand. Would countries have similar characteristics in their education policies, these two elements could presumably lead to a Kuznets curve, because $G_{H}$ decreases with $H$ (therefore the level and concentration effects go in opposite directions). However, country characteristics differ. In the process of human capital accumulation, some countries continue to implement regressive education policies while others implement progressive policies, and the existence of such differences may blur the Kuznets curve effect. This conclusion is consistent with the usual interpretation of the failure of empirical estimations of the Kuznets curve, particularly in panel data sets, which is that the relation between economic growth and changes in income distribution is country-specific, and depends on each country institutional setting.

\section{Empirical estimation}

Following our previous calculations, we will assume that the concentration of human capital in a country $i$ is connected to its educational capital and to the characteristics of its schooling policy by the following relation:

$\ln \left(1-G_{i t}\right)=\ln \left(H_{i t}\right)+\Gamma\left(\alpha_{i}\right)+\varepsilon_{i t}$

Where $i$ and $t$ are country and time indices, $\Gamma$ integrates the consequences of the structure of schooling ratios (represented here by the vector $\alpha_{i}$ ), and $\varepsilon_{i t}$ is a random residual.

This relation can be successfully tested with the data produced by Thomas, Wang and Fan (2000), as illustrated in Figure 3, which reveals a close link between the aggregate human capital level and its Gini concentration index. ${ }^{2}$

\footnotetext{
${ }^{2}$ The human capital data are those from the Barro and Lee database, used by Thonaw, Wan and Fan (2000) to compute the Gini index.
} 
Figure 3: Relation between aggregate level and concentration of human capital

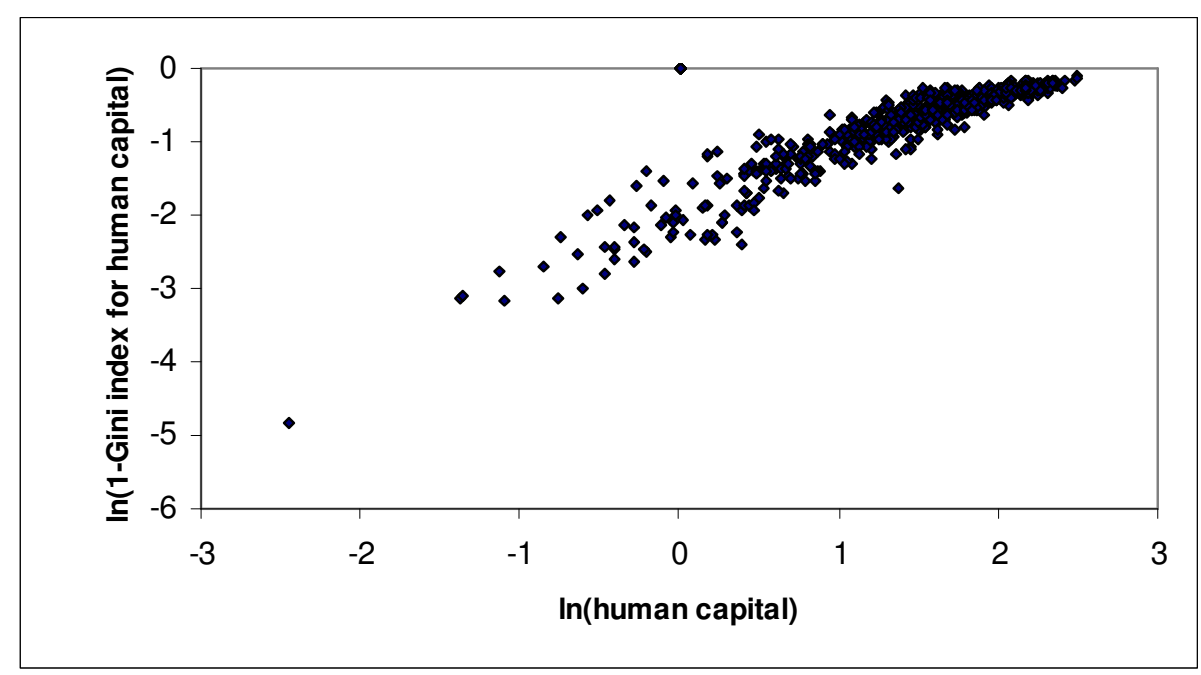

These data cover a panel of 85 countries over 7 time periods (on a quinquennial frequency from 1960 to 1990). From these data, it is possible to estimate a log-linear relation between $1-G$ (one minus the Gini concentration index) and $H$ (the level of human capital), corresponding to the previous equation (in which we expect the slope to be close to 1). Usual (Fisher and Hausman) tests show that this relation presents significant country fixed effects, which correspond to the $\alpha_{i}$ in the previous equation.

However, it is possible that the structure of schooling ratios depends itself on the aggregate level of human capital. This will be the case, for instance, if the supply of education depends on the aggregate human capital already available in the economy. Under such an hypothesis, it is likely that tertiary education enrolment ratios will depend more on $H$ than secondary enrolment ratios, which will depend more on $H$ than primary enrolment ratios. To take into account this possible influence of $H$ on the structure of the ratios of schooling and therefore on $\Gamma$, we also introduce the hypothesis that $\Gamma$ depends not only on the $\alpha_{i}$, but also on $H$, according to a relation which is not necessarily monotonous (we introduce for that matter a quadratic form). 
Table 1: Estimation of the relation between the level and the concentration of human capital (fixed effect model)

\begin{tabular}{|c|c|c|c|c|}
\hline & \multicolumn{4}{|c|}{ Dependent Variable: $\ln (1-G)$} \\
\hline & \multicolumn{2}{|c|}{$\begin{array}{l}\text { Elasticity of } 1-\mathrm{G} \text { with respect to } \mathrm{H} \\
\text { Non-constrained }\end{array}$} & \multicolumn{2}{|c|}{$\begin{array}{l}\text { Elasticity of } 1-\mathrm{G} \text { with respect to } \mathrm{H} \\
\text { Constrained to unity }\end{array}$} \\
\hline & Equation 1 & Equation 2 & Equation 3 & Equation 4 \\
\hline \multicolumn{5}{|l|}{ Explanatory variables } \\
\hline \multirow[t]{2}{*}{$\operatorname{Ln}(\mathrm{H})$} & 1.064 & 1.193 & 1 & 1 \\
\hline & $(0.026)$ & $(0.040)$ & & \\
\hline \multirow[t]{2}{*}{$\mathrm{H}$} & -0.124 & -0.230 & -0.109 & -0.120 \\
\hline & $(0.008)$ & $(0.025)$ & $(0.005)$ & $(0.012)$ \\
\hline \multirow[t]{2}{*}{$\mathrm{H}^{2}$} & & 0.007 & & 0.001 \\
\hline & & $(0.002)$ & & $(0.001)$ \\
\hline Fisher Test & $F(84,496)=17.3$ & $F(84,495)=18.2$ & $F(84,497)=17.3$ & $F(84,496)=17.1$ \\
\hline \multirow[t]{2}{*}{ Hausman Test } & $X^{2}(2)=36.0$ & $X^{2}(3)=39.6$ & $X^{2}(1)=36.3$ & $X^{2}(2)=39.3$ \\
\hline & \multicolumn{4}{|c|}{ Average distances from average fixed effects by region } \\
\hline \multirow[t]{2}{*}{ Latin America } & 0.019 & 0.031 & 0.028 & 0.033 \\
\hline & $(0.008)$ & $(0.008)$ & $(0.007)$ & $(0.008)$ \\
\hline \multirow[t]{2}{*}{ South Asia } & -0.281 & -0.297 & -0.288 & -0.293 \\
\hline & $(0.020)$ & $(0.020)$ & $(0.020)$ & $(0.020)$ \\
\hline \multirow[t]{2}{*}{ East Asia } & -0.008 & 0.006 & 0.000 & 0.005 \\
\hline & $(0.010)$ & $(0.010)$ & $(0.012)$ & $(0.010)$ \\
\hline \multirow[t]{2}{*}{ MENA } & -0.282 & -0.284 & -0.287 & -0.289 \\
\hline & $(0.013)$ & $(0.014)$ & $(0.014)$ & $(0.014)$ \\
\hline \multirow[t]{2}{*}{ Sub-Saharan Africa } & -0.021 & -0.032 & -0.030 & -0.034 \\
\hline & $(0.016)$ & $(0.016)$ & $(0.015)$ & $(0.016)$ \\
\hline \multirow[t]{2}{*}{ CEECs } & 0.153 & 0.160 & 0.152 & 0.153 \\
\hline & $(0.019)$ & 0.019 & 0.019 & $(0.019)$ \\
\hline \multirow[t]{2}{*}{ OECD } & 0.156 & 0.144 & 0.152 & 0.150 \\
\hline & $(0.014)$ & $(0.014)$ & $(0.014)$ & $(0.014)$ \\
\hline
\end{tabular}

Note: standard-deviations between brackets. 
The results of these estimations show that, effectively, the elasticity of $1-G$ to $H$ is close to 1 , even though it is significantly higher than 1 in our estimations. A constrained estimation, in which we suppose that this elasticity is exactly equal to 1 , gives very similar results.

The estimations of fixed effects inform us about the consequences of national education policies on the disparity of the distribution of human capital. To synthesize these observations, we have calculated the average of these fixed effects by region and tested whether they were different from the average calculated on the whole set of observations. These various results appear in the Table 1.

In this table, a positive sign for fixed effects indicates that the concerned region has, ceteris paribus, school policies characterized by a relatively equalitarian distribution of education in the population. All the fitted equations show that the developed countries (OECD), the Central and Eastern European Countries (CEECs) and those of Latin America have school policies more equalitarian than the average. The East Asian countries have policies comparable to the average. On the contrary, the South Asia, MENA and sub-Saharan Africa regions have relatively inequitable education policies. Concerning sub-Saharan Africa, the inequitable bias (significant at the level of 5 percent in three regressions and at the level of 20 $\%$ in the fourth) is however relatively moderate.

To summarise, the very strong concentration of human capital observed in sub-Saharan Africa (and in MENA and South Asia as well) is only partly the result of the weakness of its educational development level: it results also from inequitable education policies. As a consequence, increasing the average education intake in population will not necessarily benefit to the poorest segments of the population in those regions, in absence of change in their education systems.

\section{The arbitrage between the primary, secondary and tertiary education in sub-Saharan Africa}

Weak levels, and strong concentration, of human capital in sub-Saharan Africa result above all from the weak efforts devoted to primary schooling, so that a significant proportion of the 
population has no access to any education. It is interesting to compare in this respect the policies led in sub-Saharan Africa with those led in the other developing regions.

However, this comparison cannot be made directly, because the structure of schooling evolves as education develops, with first of all a growth of the enrolment rates in the primary level, then in the secondary level and finally in higher education. One can only compare the structures of the schooling ratios between countries that are at the same level of educational development.

Knowing that sub-Saharan Africa is very late in human capital development with regard to the other regions, we suggest comparing sub-Saharan Africa of today with developing countries which, at the beginning of the 1960 decade, had a level of educational development comparable to that the current African level. These countries are most of Latin American and East Asian countries, with the exception of some Latin American countries (Argentina, Chile, Trinidad and Tobago), which had already in 1960 levels of human capital close to those of developed countries, with on average number of years of schooling in the working-age population higher than 6 years. ${ }^{3}$

To perform this comparison, we used the human capital data produced by Cohen and Soto (2002), which have the merit to provide complete estimations on the level of human capital for a rather large number of country from 1960 to 2000, and are in principle of better quality than the data of Barro and Lee used by Thomas, Wang and Fan (2000). ${ }^{4}$ This provides a relatively large sample of observations, including, after crossing with the schooling data (source UNESCO), 23 African countries, 20 Latin American countries and 8 East Asian countries.

These data reveal first of all that, at identical levels of human capital, the sub-Saharan African countries have in 1990 primary rates of schooling lower by 9 percentage points than East Asian and Latin American countries in 1960. ${ }^{5}$ They have therefore schooling policies sharply less favorable to primary education than the countries which preceded them on the path of

\footnotetext{
${ }^{3}$ Symmetrically, we did not take into account, in sub-Saharan Africa, Mauritius and Zimbabwe, which have from 1990 an average human capital level in the working-age population above 6 years.

${ }^{4}$ But unfortunately they are not necessarily consistent with the concentration data, based on Barro and Lee data, and they are available only with a decennial frequency; this is why we used Barro and Lee data in the previous section.

${ }^{5}$ This difference is statistically significant at the level of 6 percent.
} 
development. This is illustrated in Table 2 (first equation) and Figure 4. Still this comparison masks probably even higher differences in access of the children to school, because it is based on gross enrolment rates rather than on (rarely available) net school enrolment rates. Factual observations in various African countries suggest indeed that drop-outs and repetitions are particularly frequent there, what makes that the gross enrolment rates produce a particularly optimistic picture of African primary education systems.

Table 2: equations of comparison of education policies in Africa (1990) and East Asia \& Latin America (1960)

\begin{tabular}{|lccc|}
\hline \multicolumn{3}{|c|}{ Dependent variable } \\
& $\mathrm{s}_{1}$ & $\mathrm{~s}_{2} / \mathrm{s}_{1}$ & $\mathrm{~s}_{3} / \mathrm{s}_{1}$ \\
\hline Explanatory & & & \\
variables & & & \\
$\mathrm{H}$ & 9.85 & 4.06 & 0.75 \\
& $(1.32)$ & $(0.80)$ & $(0.25)$ \\
African dummy & -8.40 & 10.34 & -1.33 \\
& $(4.33)$ & $(2.64)$ & $(0.83)$ \\
intercept & 51.83 & 4.75 & 2.01 \\
& $(5.62)$ & $(3.42)$ & $(1.06)$ \\
& & & \\
$\mathrm{R}^{2}$ & 0.56 & 0.39 & 0.22 \\
& & & \\
numb. of obs. & 56 & 56 & 53 \\
Note: standard-deviations between brackets.
\end{tabular}

Figure 4: Comparison of the primary school enrolment rates in sub-Saharan Africa (1990) and in Latin America \& East Asia (1960)

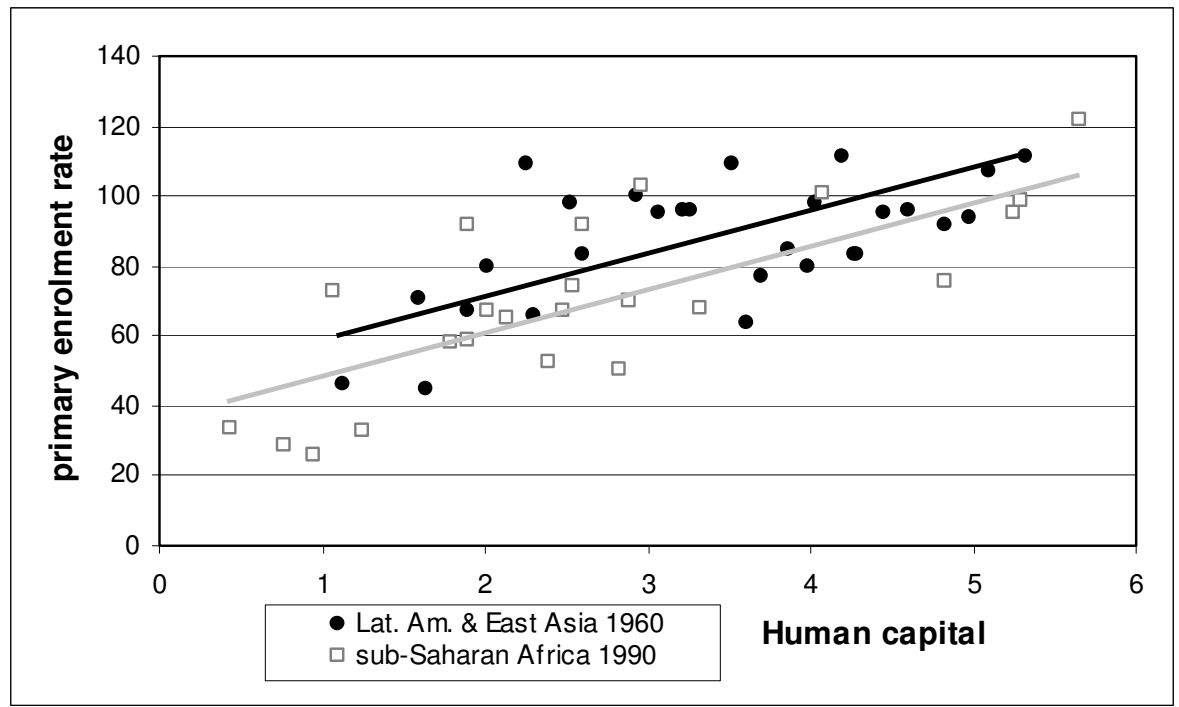


At the same time as they implement policies unfavourable to primary education, the African countries relatively favour secondary education. This is shown in Table 2 (second equation) and in Figure 5, which compares the ratios of secondary to primary schooling in Africa in 1990 and in Latin America and East Asia in 1960. This indicator, defined as the variable $\sigma$ in the previous section, can influence the disparities of distribution of human capital, in the sense of an escalation of inequalities when $\sigma$ increase, at least for the average structure of the schooling ratios observed in Africa. ${ }^{6}$ This difference is rather big: for identical human capital, the sub-Saharan Africa countries have in 1990 a secondary to primary schooling ratio superior by 10 percentage points to the ratio observed in Latin America and East Asia in 1960, i.e. $50 \%$ more than the average ratio observed in emerging countries in 1960 , which was around 20 percent. $^{7}$

Figure 5: Comparison of secondary to primary schooling ratios in sub-Saharan Africa (1990) and in Latin America \& East Asia (1960)

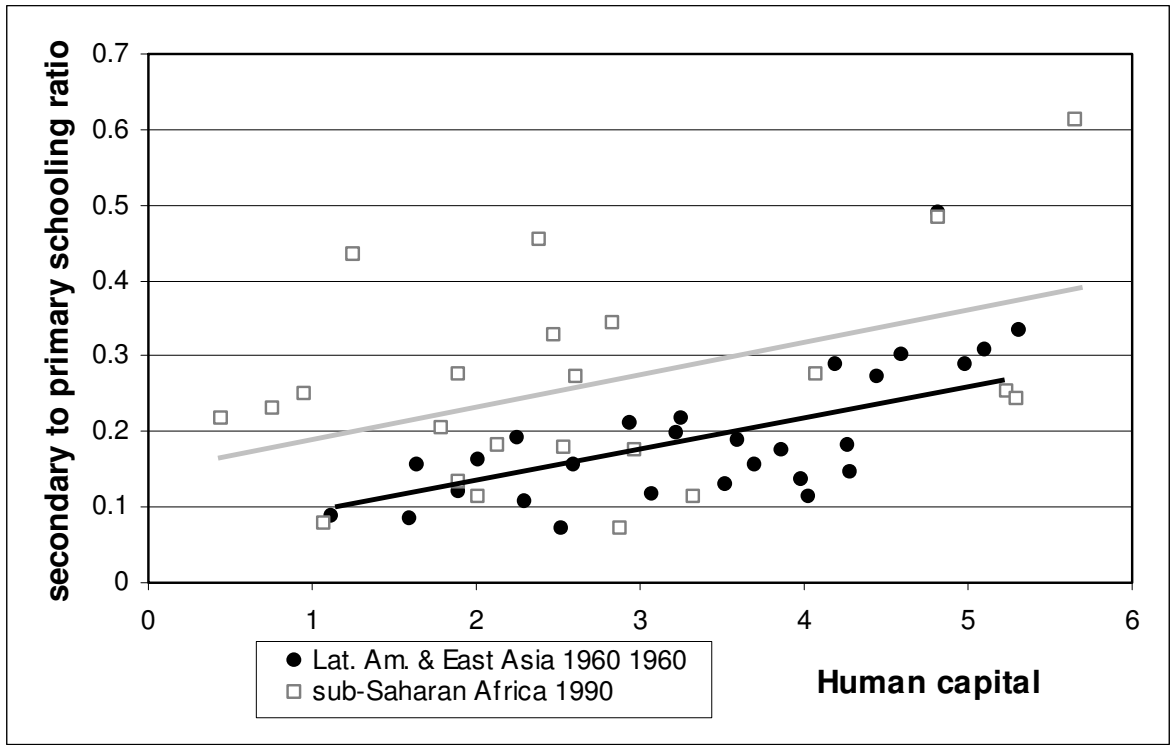

To better visualize the difference of education policies implemented in sub-Saharan Africa and in Latin American and East Asian emerging countries over the past decades, we report in Figure 6 the evolution over the past three decades of primary and secondary school enrolment

\footnotetext{
${ }^{6}$ The formula developed in the previous section suggests that the Gini index of human capital is not a monotonously increasing function of $\sigma$, but it is increasing for the values of $\sigma$ and $\tau$ observed in our sample.

${ }^{7}$ This difference is statistically significant at the level of 1 per thousand.
} 
ratios in the median sub-Saharan African country (numbers) and their quotients to the same ratios observed in the median emerging country in 1960 (bars). It is clear from Figure 6 that, although sub-Saharan African countries had secondary school ratios already comparable in 1980 to those observed in the emerging countries of 1960, and close to double in 1999, they have not yet reached in 1999 the same level of primary enrolment as emerging countries of 1960.

Figure 6: median sub-Saharan African country primary and secondary enrolment ratios (1980, 1990 \& 1999) compared to the median emerging country primary and secondary enrolment ratios (1960)

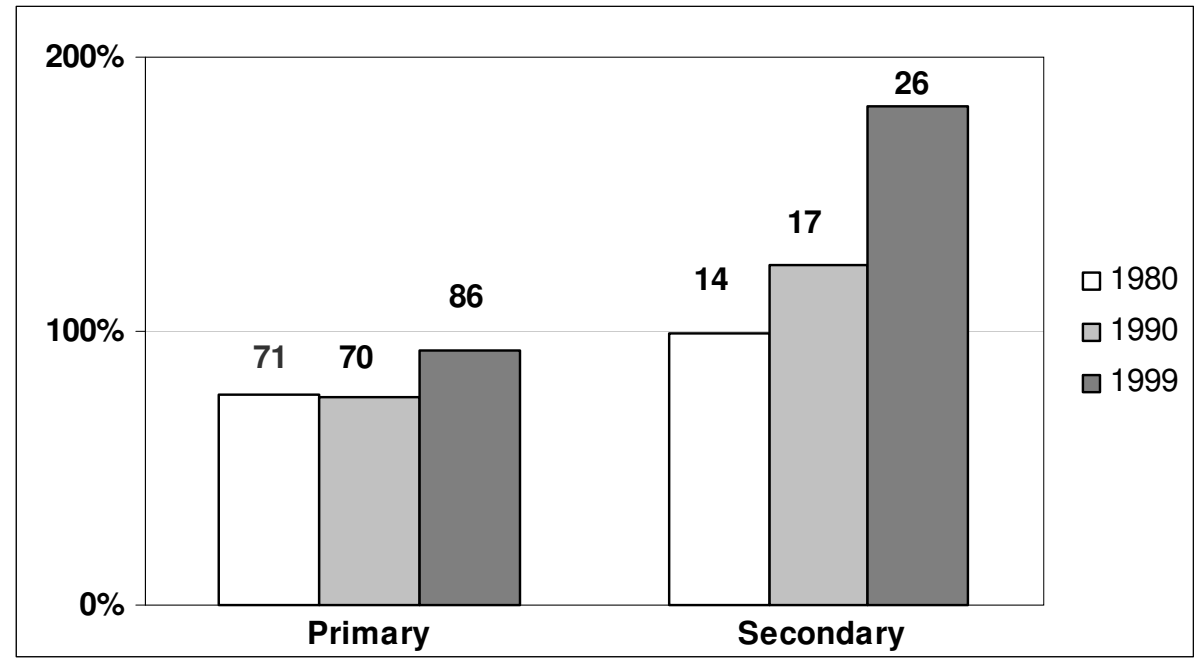

Finally, we compare the relative tertiary to primary schooling ratios on the same sample of observations. This comparison (Table 2, third equation and Figure 7) reveals a total absence of difference between sub-Saharan Africa of 1990 on one hand and Latin America and East Asia of $1965^{8}$ on the other hand. ${ }^{9}$

\footnotetext{
${ }^{8}$ For lack of data for 1960, data for the Latin America and East Asia are for 1965.

${ }^{9}$ This figure excludes the Philippines, which present here an outlier (with and extremely high tertiary enrolment rate) with regard to the other countries of the sample.
} 
Figure 7: Comparison of tertiary to primary schooling ratios in sub-Saharan Africa Africa (1990) and in Latin America \& East Asia (1960)

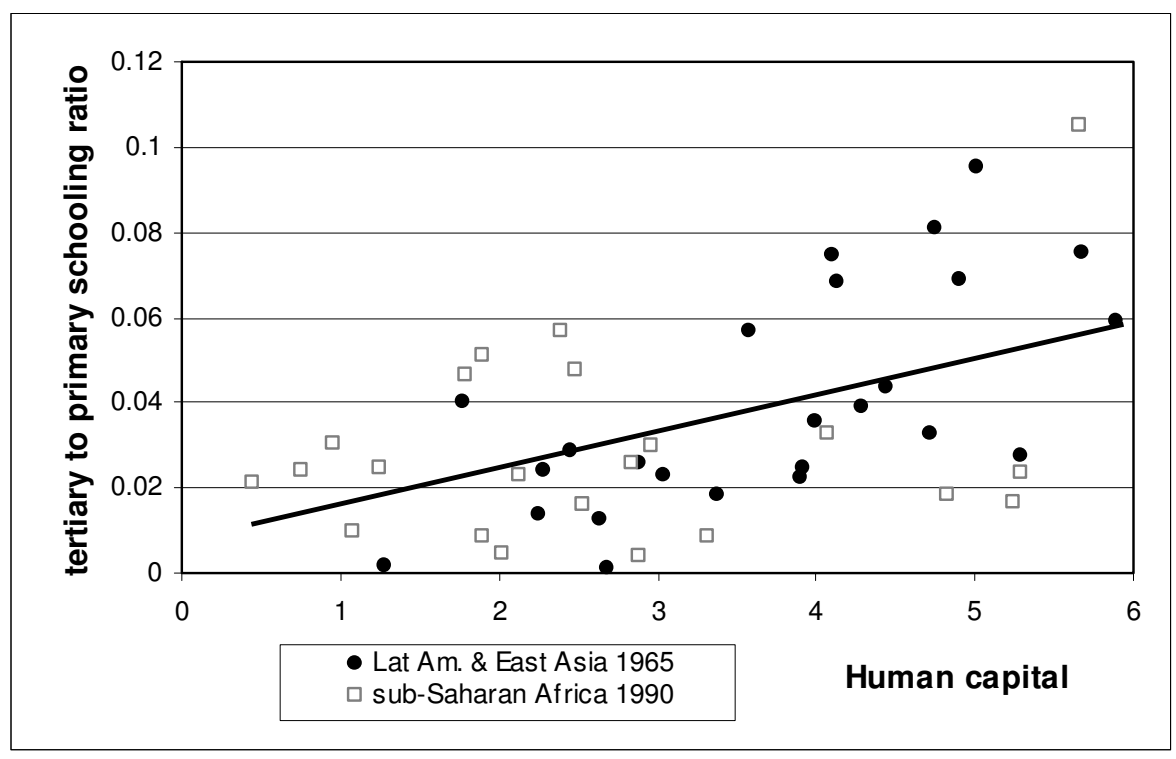

It seems in conclusion that sub-Saharan Africa has, on average, school policies unfavourable to primary education, and biased in favour of secondary education. These observations confirm those of the previous section, as far as they allow interpreting the inequitable bias of policies implemented in sub-Saharan Africa, by comparison to those of Latin America and East Asia. There is not on the other hand any systematic bias in favour of higher education, at least as regards the rates of schooling.

\section{How to explain the African bias against primary education?}

In order to improve the poverty impact of education policies, a lot could be done by simply switching public education expenditure to primary schools. In principle, this should not have any negative impact on growth, since the available international evidence suggests that the social return to primary education is higher that the return to secondary education, which is in 
turn higher than the return to tertiary education (Psacharopoulos, 1994) ${ }^{10}$. Against this proposal, one could argue that all countries need skills at different levels, and not only at the primary level. This is true, but not to the point that sub-Saharan Africa would need a bigger proportion of higher qualifications than East Asia and Latin America did in the 1960s. One needs therefore to search explanations of this bias of the schooling structure against primary education.

One first possible explanation can be searched in the behaviour of demand for education. A number of papers in the literature on income distribution and economic growth have introduced the idea that an unequal distribution of incomes may reduce education demand, in the presence of imperfect capital markets. In Galor and Zeira (1993), for instance, the proportion of population which goes to school is higher when incomes are more equally distribution: for individuals who are initially relatively poor, the opportunity cost of school attendance is too high because they would have to borrow initially to go to school.

Although data are sketchy, it seems true that the income distribution is on average more concentrated in Africa than in East Asia. The average of Gini indexes of African countries observable in the 1990s is equal to 48, against 42 in East Asia ${ }^{11}$. However, it is also lower than for Latin America (50). Moreover, MENA countries and South Asian countries have on average relatively low Gini indexes (respectively 35 and 38) but a high concentration of human capital. Therefore, there is not strong evidence that regions where income is more equally distributed are also regions where education is highly concentrated.

Moreover, on analytical grounds, we need again to disentangle level and concentration effects, when analysing such a relation. In a theoretical framework such as the one propose by Galor and Zeira (1993), there is only one level of education, and therefore it is not possible to separate these two effects. An extension of this framework would lead to consider (at least) two levels of education. The income distribution/imperfect capital market effect should be more sensitive on secondary than on primary education (and more on tertiary than on secondary education), because the opportunity cost of education is growing with its level. Therefore, in such a framework, the relative enrolment rates $\sigma$ and $\tau$ would reduce, rather than

\footnotetext{
${ }^{10}$ This result is consistent with the Mincerian hypothesis of a constant private return to education, given that public costs of education increase a lot from primary to secondary levels, and from secondary to tertiary levels.

${ }^{11}$ Source World Bank, World Development Indicators.
} 
increase, with income concentration and capital market imperfections. This means that, after controlling for the aggregate level of education, income concentration and capital market imperfections should reduce the inequality of education distribution. Therefore, such demand side factors cannot explain the relative inequality of education distribution in Africa. ${ }^{12}$

Against this background, we need to search for explanations of the bias against primary education on the supply side, i.e. on education policies. Reducing this bias would require that the education policy be refocused on primary education. This is however easier said than done and African policy makers, and African elites in general, are usually quite reluctant to follow this route. Our interpretation is that, for reasons that are deeply rooted in history, demography and geography, this bias is part of the institutional setting of African societies.

\section{History}

First of all, the colonial legacy may play a major role. In colonial times, European rulers chose to provide education to a small elite class of people, who served as indigenous civil servants and as employees in the trading companies. ${ }^{13}$ Cogneau and Guénard (2003) emphasize that the colonial powers needed to adopt a "divide and rule" strategy, in order to prevent local population from gaining too much power, which may partly explain why they chose to educate only a little fraction of the population. Those people were generally given a full primary curriculum, and for some of them secondary education as well, in a school system which favoured the quality of education, but enrolled very limited numbers of pupils. In other words, this colonial system was a sort of caricature of the current one and one may think that African policy makers, who were all, initially, part of this indigenous elite trained in the colonial education system, did not want to change it. ${ }^{14}$

At the time of the Independences, there was also a generalized feeling among African policy makers that they needed to invest significant amounts of resources in building a modern civil service, needed to promote economic development. Although this objective has not been met,

\footnotetext{
12 This may, however, partly explain why education is more unequally distributed in MENA and South Asia regions than in East Asia and in Latin America.

${ }^{13}$ A superb illustration of this aspect of the colonial ruling system in francophone Africa will be found in the memories of Amadou Hampaté Bâ.

${ }^{14}$ An anecdotal example of the importance attached to secondary education for a small elite can be found in Senegal in post-Independence, where latin studies were still compulsory at junior high school, while they were not anymore in France, and while a majority of children could not access to primary school.
} 
it has implied that many efforts were devoted to educate future civil servants. Again, this has led to a system where providing a secondary curriculum to a relatively small elite was considered as a critical objective, while the vast majority of children were not given the opportunity to attend school. Besides, this system has also resulted in the development of pervasive rent-seeking behaviours, given that until the adjustment programs of the 1980s all graduates from secondary school were guaranteed a civil servant position. As a consequence, not only education has been unequally distributed, but it has favoured the spreading of rentseeking behaviours, and therefore it could not promote growth either.

\section{Demography}

Demography can also explain part of the bias observed in African education policies. African countries have a very high population at secondary and tertiary school age, significantly higher that in Asia and Latin America in the 1960s, and this difference is growing over time, due to demographic factors. Possibly the best indicator of these differences is given by the median age of population, as reported in Figure 8. ${ }^{15}$

These demographic characteristics result in the fact that teenagers and young adults form a very vocal and rather powerful part of the population. Particularly those living in cities have a significant impact on the political decision processes. They can destabilise a government through riots and other forms of demonstration, and they do so quite often. Sometimes this is for good reasons, such as in Mali in 1991 when students' demonstrations played a major role in the eviction of President Moussa Traoré, but very often they behave exactly as a pressure group trying to protect their vested interests.

A consequence of this is that in most sub-Saharan African countries, government spend a lot of resources in the education budget for purses and other social expenditure in favour of high school pupils and university students. This implies that the total cost of secondary (and tertiary) education is very high, and leaves usually only less than half of the education budget available for primary schools. Under such conditions, although African government spend significant budgets in education, they have few resources available to expand the primary school system.

\footnotetext{
${ }^{15}$ Source of data : UN Population Division website : http://esa.un.org/unpp/
} 
Figure 8: Median age of population in Africa, Asia and Latin America

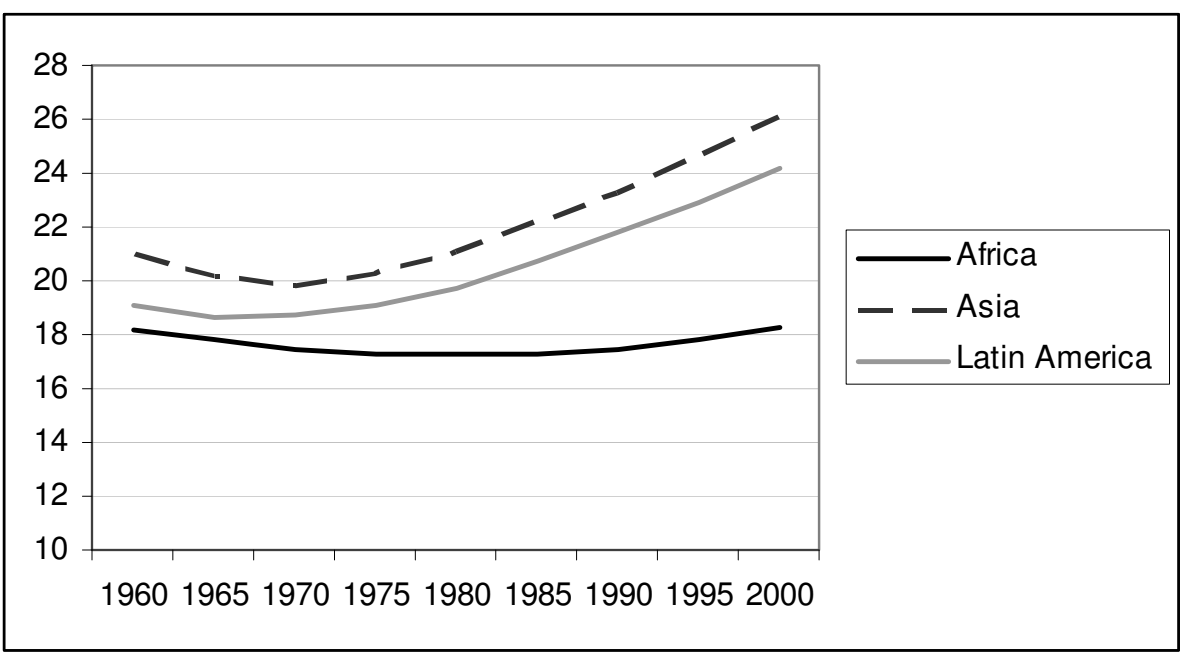

Geography

Finally, the bias against primary education is part of the urban bias (Lipton, 1977), given that, almost by definition, expanding the primary school system would imply investing more in education infrastructure in the rural areas, while secondary schools and universities are located in the main cities. Of course, this urban bias may have many ramifications and explanations, which go beyond the scope of this paper.

One specific aspect, which may have a significant impact on education policies, is the small density of population in Africa, which results in the scattering of population in vast areas and consequently leads to significant transportation costs. This may explain why government do not expand the primary education system in rural areas, where population is too much dispersed to justify building schools in each and every village, and where also school teachers do not accept to be posted. East Asia has a much higher population density, and consequently does not face the same issue. In Latin America, the population density is similar to that observed in Africa, but a majority of the population already lives in cities, which means that the divide between rural and urban population has a much smaller impact. Moreover, Latin 
America has a density of its road network comparable to that of East Asia, and 2.6 times higher than Africa. ${ }^{16}$

\section{Conclusion}

Our findings suggest that education policies are on average biased against primary education in sub-Saharan Africa. This is both inefficient and inequitable. The inefficiency of these policies implemented by most African government lies simply in the well documented fact that the social rate of return to primary education is higher than the social rate of return to secondary and tertiary education. Moreover, this choice is linked to the tendency to favour classical high school studies, a factor which contributes to the production of rent-seekers, who will, after completing secondary school or some tertiary education, look for a job in the civil service.

This choice is also inequitable, and certainly contributes to increase income inequality in subSaharan African countries. The Gini concentration index for human capital is on average higher than 0.6, which is much higher than the Gini concentration index calculated on incomes. The impact of this unequal distribution of human capital may be compound with the fact that, following the Mincer theory of earnings, the income generated by human capital is, at the micro-economic level, more than proportional to this human capital.

In the recent empirical literature on income distribution, different evaluations based on computation of the implicit income transfer to the households through public education expenditure often lead to the same conclusion on the inequity of education policies. Such polices implicitly transfer resources to the middle class and the wealthier sections of the population rather than to the poor. The same is true for health public expenditure, which contribute also to human capital building. ${ }^{17}$ These findings can be related to our results: not only governments implement inequitable education policies, through spending too little on primary education, but also they reproduce the existing social classes, given that only children of the wealthiest have a large access to secondary and tertiary education.

\footnotetext{
${ }^{16}$ Source : World Bank, World Development Indicators

${ }^{17}$ For some examples see C. Morrisson, ed. (2002).
} 
However, many African policy makers and other members of the elite are reluctant to reverse this bias. Our interpretation is that such behaviours are deeply rooted in institution-related factors: history, with the colonial legacy, demography, with the heavy weight of teenagers and young adults in population, who form a significant pressure group in the African political landscape, and geography, which reinforces the urban bias.

Not all sub-Saharan African countries necessarily behave this way. For instance, Uganda has built a virtually universal primary education system starting in 1997. But Uganda is a rather special case, where the new government in place since 1986 had to rebuild the whole society and economy after so many years of dictatorship and civil wars. Presumably very special circumstances are required to produce the institutional changes that are necessary to reverse the current African bias against primary education.

It would be certainly desirable to discuss further the cases of MENA and South Asian countries, in which we have observed similar regressive bias in education policies. Although a deeper analysis would be necessary, we submit that similar explanations could be proposed for these countries: they have in common with sub-Saharan Africa a comparable colonial legacy, and a similar post-colonial history with respect to the implementation of education policies targeted at building a well-educated administrative elite. 


\section{References}

Berthélemy, J.C., C. Pissarides and A. Varoudakis (2000), « Human Capital and Growth: The Cost of Rent Seeking Activities ", in: The Determinants of Economic Growth, M. Oosterbaan, T. de Ruyter van Steveninck et N. van der Windt (ed.), Kluwer Academic Publisher.

Castello, A. et R. Domenech (2002), «Human Capital Inequality and Economic Growth : Some New Evidence », The Economic Journal, vol.112, mars.

Cogneau, D., and C. Guénard (2003), «Colonization, Institutions, and Inequality, A Note on Some Suggestive Evidence, DIAL working paper n²003/05.

Cohen, D., and M. Soto (2001), «Growth and Human Capital : Good Data, Good Results », OECD, Development Centre, Technical Paper n¹79.

Galor, O., and J. Zeira (1992), "Income Distribution and Macroeconomics", Review of Economic Studies, vol. 60.

Knight, J.B., and R.H. Sabot (1983), "Education Expansion and the Kuznets Effect", American Economic Review, vol.73.

Lipton, M. (1977), Why Poor People Stay Poor: Urban Bias in World Development, Cambridge: Harvard University Press.

Lopez, R., V. Thomas et Y. Wang (1998), "Addressing the Education Puzzle: The Distribution of Education and Economic Reforms », mimeo, Banque Mondiale.

Morrisson, C. (ed.) (2002),: « Education and Health Expenditure and Poverty Reduction in East Africa: Madagascar and Tanzania », OECD, Development Centre, 2002.

Pritchett, L. (2001), «Where Has All the Education Gone?», The World Bank Economic Review, vol.15, n³.

Psacharopoulos, G. (1994), «Returns to Investment in Education : A Global Update», World Development, vol.22, $\mathrm{n}^{\circ} 9$.

Thomas, V., Y. Wang et X. Fan (2000), « Measuring Education Inequality : Gini Coefficients of Education », mimeo, Banque Mondiale. 